\title{
A GEOMETRICAL APPROACH TO DERIVING A BUSHING HEIGHT EQUATION FOR THERMAL FRICTION DRILLING
}

\section{GEOMETRIČNI PRISTOP K IZPELJAVI ENAČBE ZA DOLOČITEV VIŠINE BLAZINICE, NASTALE PO TERMIČNEM TORNEM VRTANJU}

\section{Zülküf Demır}

Batman University, Faculty of Engineering and Architecture, Department of Mechanical Engineering, Kuyubasi Village, Bati Raman Campus, 72100 Batman, Turkey

Prejem rokopisa - received: 2018-07-02; sprejem za objavo - accepted for publication: 2018-11-06

doi:10.17222/mit.2018.134

\begin{abstract}
The main purpose of thermal friction drilling is to increase the connection strength with the help of bushing formation. Therefore, the bushing formation and its geometry are of great interest. In this study, the bushing shapes obtained from the literature are analyzed geometrically according to their outer curve lines. These curve lines resemble a graph of parabola with varying slopes. The total volume of the evacuated material is completed when the tool cylindrical region sinks into the workpiece (t) $\mathrm{mm}$ in depth. It is accepted that approximately by the time when the tip of the tool reaches the half thickness of the material, the evacuated material forms a flake. By subtracting the flake volume $\left(V_{\mathrm{C}}\right)$ from the total evacuated-material volume $\left(V_{\mathrm{E}}\right)$, the volume of the bushing shape $\left(V_{\mathrm{B}}\right)$ is determined. From the obtained equation, the bushing height is found, depending on the hole diameter $(d)$, sheet-material thickness $(t)$, tool conical angle $(\beta)$, feed rate $(f)$, which can be selected by the operator, and also equation constant $\mu$. Using the bushing-height values, gained from the literature, the limit of the constant is specified as $0.001 \leq$ $\mu \leq 1.2$ for thermal friction drilling of all kinds of materials. By comparing the experimental bushing-height results, obtained from the literature, with the modeling data, it is observed that the equation constant $(\mu)$ shows a simultaneous alteration with the material thickness $(t)$, hole diameter $(d)$ and tool conical angle $(\beta)$, but an adverse alteration with the feed rate $(f)$.

Keywords: thermal friction drilling, conical-tool geometry, bushing shape, bushing height, bushing equation
\end{abstract}

Glavni namen termičnega tornega vrtanja je povečanje vezne trdnosti med osnovnim materialom in med vrtanjem za vrtino nastalo posebno obliko (blazinico). Zato sta nastanek te blazinice za vrtino in njena geometrija zelo zanimiva. Avtorji geometrično analizirajo blazinice, nastale po tornem vrtanju, glede na njihov zunanji obris. Podatke o njihovih geometrijah so zbrali v podani literaturi. Obrisi nastalih blazinic spominjajo na parabole $\mathrm{z}$ različnim nagibom. Pretvorba izvrtanega materiala $\mathrm{v}$ blazinico se zaključi, ko se cilindrični del vrtala potopi v material za globino $(\mathrm{t}) \mathrm{v} \mathrm{mm}$. Splošno je sprejeto, da dokler konica vrtala ne doseže približno polovice debeline materiala, izvrtani material tvori obliko ostružka. $Z$ odštevanjem volumna ostružka $\left(V_{\mathrm{C}}\right)$ od celotnega volumna $\left(V_{\mathrm{E}}\right)$ lahko izračunamo volumen nastale blazinice $\left(V_{\mathrm{B}}\right)$. Višino nastale blazinice lahko tako izračunamo v odvisnosti od premera vrtine $(\mathrm{d})$, debeline materiala $(\mathrm{t})$, kota konice vrtala $(\beta)$, hitrosti prodiranja vrtala $\mathrm{v}$ material $(f)$, ki jo določi/izbere operater na stroju in konstante $\mu$. Iz podatkov, zbranih v literaturi za nastale višine blazinic, ima konstanta vrednosti med $0.001 \leq \mu \leq 1.2$ za termično vrtanje vseh vrst materialov. Primerjava eksperimentalnih rezultatov za višino blazinice, dobljenih v literaturi, z modelnimi podatki kaže, da je konstanta $(\mu)$ istočasno odvisna od debeline materiala $(t)$, premera vrtine $(d)$, koničnosti konice vrtala $(\beta)$, medtem ko ima hitrost prodiranja vrtala v material $(f)$ obraten učinek.

Ključne besede: termično torno vrtanje, konična geometrija orodja, oblika in višina izvrtane blazinice, enačba za izračun višine blazinice

\section{INTRODUCTION}

Friction drilling is a hole-production method, in which the material is not cut by the tool. In this manufacturing process, a sample material is heated up by the effect of friction, generated between the rotating conical tool and the drilled material. The rising temperature causes the sample to soften. Then, the softened material is pushed downward by the tool, in the direction of the rotating conical tool proceeding into the sample to generate a bushing formation, increasing the connection strength in the sheet materials. Therefore, a bushing formation is the main goal of thermal friction drilling. However, the microstructure of a bushing formation

*Corresponding author e-mail:

zulkuff75@gmail.com changes due to the deformation effect during the process. Thus, the bushing has a microstructure with grains smaller than those of the base material in both the longitudinal and transverse directions due to the effect of the conical-tool rotating motion and pressure. Therefore, the strength of the flowed material increases when approaching the surface of the thermal friction drilled hole. ${ }^{1}$ A bushing with a cylindrical shape, having no cracks or petal formation on it, increases the clamping load. ${ }^{2}$ Moreover, a higher bushing length leads to a larger screwing area as well as increasing the connection strength of the sheet materials. ${ }^{3}$ The bushing shape, especially the geometrical dimensions of a bushing, such as the bushing height and wall thickness, depends on both the thickness of the drilled material and the diameter of the thermal friction drilled hole, and hence it 
depends on the ratio $(t / d)$ of the material thickness $(t)$ to the hole diameter $(d){ }^{4}$

The bushing shape requires five steps to be complete and categorized according to the geometrical regions of the conical tool and proceeding dimension of the tool sinking into the material. As the first step, the tip of the tool contacts the material at a low peripheral speed. During the second step, the conical region of the tool advances into the material and enables it to soften in virtue of rising the frictional temperature in the contact area, between the tool conical region and the drilled material. At the third step, the cylindrical region sinks into the material and generates its final cylindrical shaping. At the fourth step, the shoulder of the tool presses the flank material, flowing in the upward direction during the operation; now the bushing formation is completed. At the last step, the thermal friction drilling operation is completed and the conical tool is removed from the drilled material. ${ }^{5,6}$ The bushing height is measured to be approximately 2-3 times the thickness of the thermal frictional drilled material. ${ }^{7,8}$

As the bushing height decreases, the spindle speed and feed rate increase. The wall thickness of the bushing formation increases as well, providing a larger screwing area, connecting with the sheet materials. ${ }^{6,9-12}$ However, the height of the bushing depends on the drilled hole diameter rather than the material thickness. This is because at the selected hole-diameter constant, the increase in the height of the bushing does not change linearly with the increase in the drilled-material thickness. ${ }^{13}$

An appropriate process temperature enables the thermal-friction-drilled material to soften, thus decreasing the deformation effect and the required bushing shape. The appropriate temperature is noticed to be approximately $1 / 2-2 / 3$ of the melting temperature of the thermalfriction-drilled material. ${ }^{14,15}$ The process temperature and deformation quantity can be identified by applying the FEM solution method. ${ }^{16}$ Moreover, the thrust force, torque and process temperature may be predicted using the FEM analysis method according to the conical-tool geometry. ${ }^{5}$

In conventional drilling operations, the chip removed from the sample as waste material during the friction thermal drilling provides for a bushing formation formed with the help of frictional heat. In the present study, the bushing shapes obtained from the literature were analyzed. Especially the outer curve of the bushing shape was geometrically investigated. In this analyzing process, a lot of bushing shapes were obtained and their outer curves were represented by a geometrical equation. In conclusion, the volume of the bushing $\left(V_{\mathrm{B}}\right)$ equalizes the difference between the volume of the total evacuated material $\left(V_{\mathrm{E}}\right)$ and the volume of the material evacuated before the tip of the tool reaches the half thickness of the drilled material. Therefore, the bushing height $\left(h_{\mathrm{a}}\right)$ can be calculated depending on the hole diameter $(d)$, material thickness $(t)$, tool conical angle $(\beta)$ and equation constant $(\mu)$.

\section{NOMENCLATURE}

$V_{\mathrm{E}}$ : The total volume of the evacuated material $\left(\mathrm{mm}^{3}\right)$

$V_{\mathrm{B}}$ : The total volume of the bushing shape $\left(\mathrm{mm}^{3}\right)$

$V_{\mathrm{C}}$ : The total volume of the tool conical region $\left(\mathrm{mm}^{3}\right)$

$V_{\mathrm{F}}$ : The volume of the flake shape $\left(\mathrm{mm}^{3}\right)$

$V_{\mathrm{M}}$ : The volume of the tip of the tool $\left(\mathrm{mm}^{3}\right)$

$V_{1 \mathrm{R}}$ : The volume of the evacuated material in one revolve of the tool $\left(\mathrm{mm}^{3}\right)$

$V_{\mathrm{nR}}$ : The volume of the evacuated material in $\mathrm{n}$ revolve of the tool $\left(\mathrm{mm}^{3}\right)$

$V_{\mathrm{s}}$ : The volume of the material, spreading to the surroundings during the thermal-friction-drilling process $\left(\mathrm{mm}^{3}\right)$

$d$ : The diameter of the friction thermal drilled hole ( $\mathrm{mm})$

$t$ : The thickness of the friction thermal drilled material (mm)

$\beta$ : Tool conical angle $\left({ }^{\circ}\right)$

$f$ : The feed rate $(\mathrm{mm} / \mathrm{min})$

$\mu, \varepsilon, \lambda, \theta, k$ : Equation constants

$h_{\mathrm{a}}$ : The bushing height $(\mathrm{mm})$

$v$ : The speed of the tool sinking into the friction thermal drilled material $(\mathrm{mm} / \mathrm{s})$

$n$ : The tool revolving cycles $\left(\mathrm{min}^{-1}\right)$

$T$ : The time of the friction thermal drilling process (s)

\section{DETERMINING THE BUSHING HEIGHT EQUATION ACCORDING TO THE TOOL AND BUSHING SHAPES}

\subsection{Geometrical formation steps of the bushing}

Although thermal friction drilling is divided into five steps in the literature, according to the relative motion, taking place between the conical tool and the drilled material, we can replace these steps by three steps according to the formation phases of bushing, as seen in Figure 1. The division made so far depends on the tool regions such as the tool tip, conical region, cylindrical region, shoulder, also taking into account the thermal friction drilled material and the contact relation between them. ${ }^{6,15}$ However, in the present paper, due to the significance of the bushing formation, the division of thermal friction drilling into different steps was made according to the formation phases of bushing. This formation depends on the flowing direction of the softened material. At the beginning of thermal friction drilling and until the tip of the conical tool reaches the half thickness of the drilled material, as seen in Figure 1a, the softened material flows in the upper direction, towards the toolshoulder region. This flowing material forms a flake, which denominates the tightness washer when entering the thermal-friction-drilled hole.

When the tip of the tool passes the half thickness of the material, while proceeding into the thermal-frictiondrilled material, the bushing starts to form, as seen in Figure 1b. In this stage, while the softened material is still flowing in the downward direction, the flake forma- 

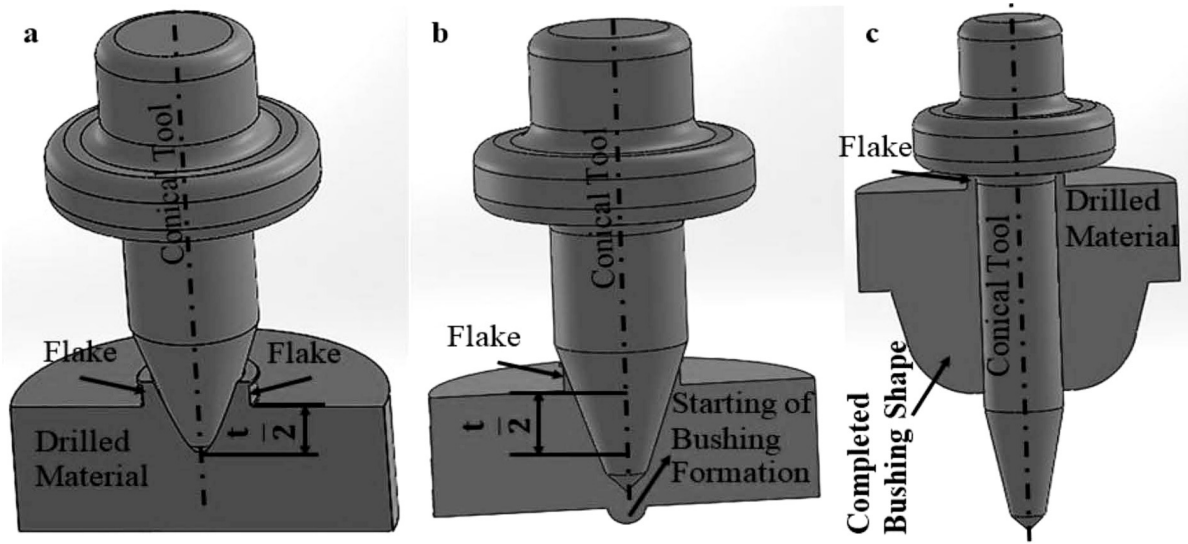

Figure 1: a) flake formation, b) start of bushing formation, c) completed bushing formation

tion is completed. The bushing formation is completed when the shoulder of the tool contacts the flake, pressing it onto the upper surface of the material, as seen in Figure 1c.

\subsection{Volume of the evacuated material according to the conical-tool geometry}

When the tip of the conical tool contacts the surface of the workpiece during the first step, as seen in Fig- ure 2, the material starts to flow away from the workpiece due to the effect of the friction and motion of the tool. When the tip of the tool sinks into the workpiece t1 in depth (between points $\mathrm{A}$ and B) during the second step, as seen in Figure 2a, the volume of the evacuated material equals the volume of the tip of the tool $\left(V_{\mathrm{M}}\right)$. As soon as the tip of the tool reaches the half thickness $(t / 2)$ of the material, the tool sinks into the workpiece between points $\mathrm{A}$ and $\mathrm{C}$ during the third step, as seen in Figure $2 \mathbf{a}$. In all the studies reported in the literature, the
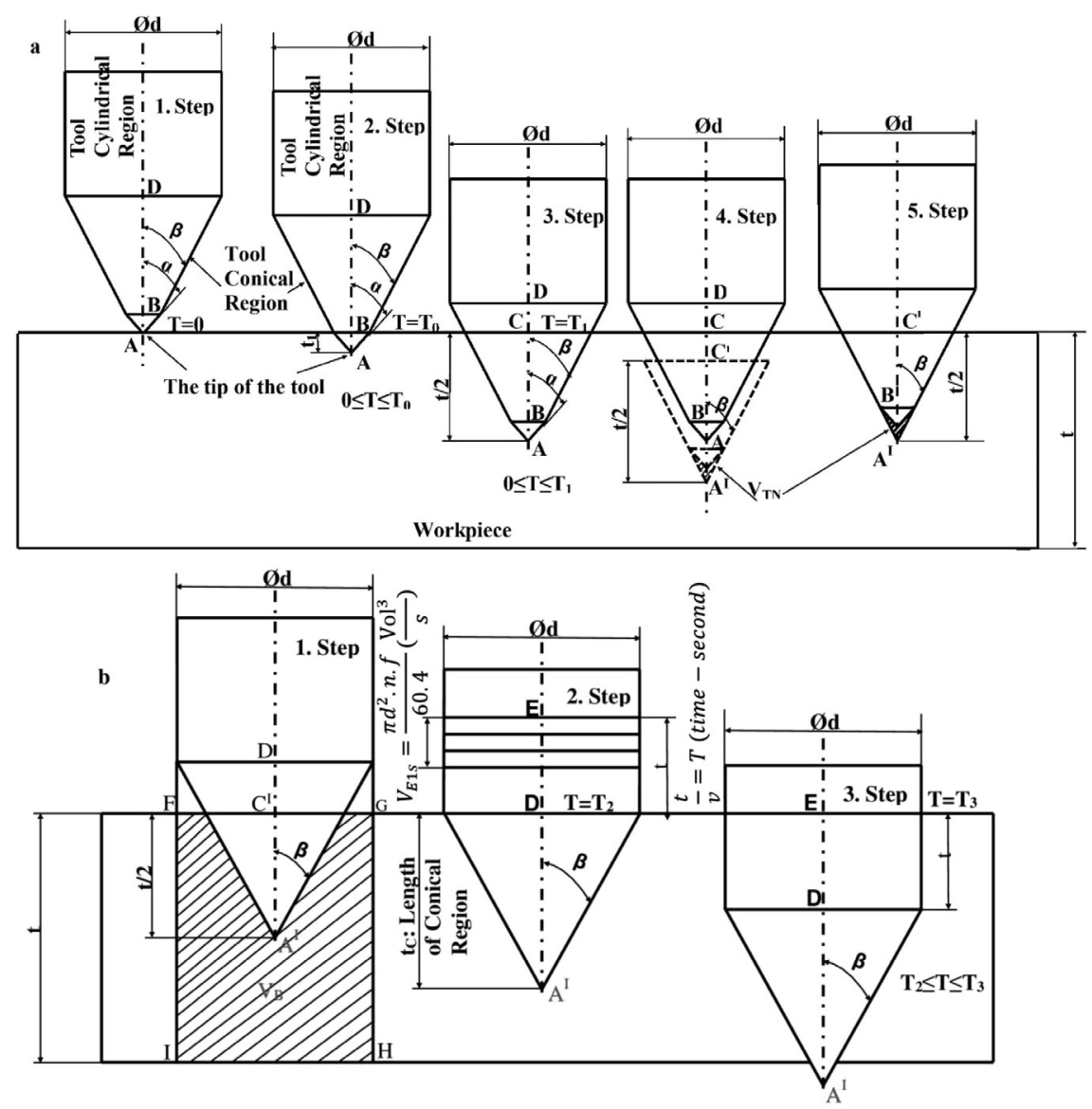

Figure 2: Evacuated-material volume: a) geometry of the tool conical region, b) volumes of the material from the tip, conical and cylindrical regions 
inclination angle of the tip of the tool $(\alpha)$ was $45^{\circ}$ and the optimum conical angle $(\beta)$ was between $30^{\circ}-36^{\circ}$. When calculating the evacuated-material volume, it is accepted that the angle of the tip of the tool $(\alpha)$ equals the conical angle $(\beta)$ in the fourth step, as shown in Figure 2a. In this case, the evacuated-material volume (VMN) is negligible in the fifth step, as seen in Figure 2a.

When the tip of the tool reaches the half thickness of the workpiece $(t / 2)$, the volume of the evacuated material $\left(V_{\mathrm{C}}\right)$, forming the flake, equals the volume of the cone of the tool between AI and CI during the first step, as seen in Figure 2b. When the tool sinks into the workpiece to point CI, the evacuated material flows upwards to form the flake. However, when the tool proceeds into the workpiece from point $\mathrm{CI}$ to the end of the process, the evacuated material forms the bushing in the second step, as indicated in Figure $\mathbf{2 b}$. The volume of the bushing equals the volume of the evacuated material when the cylindrical region of the tool sinks into the workpiece between points $\mathrm{D}$ and $\mathrm{E} \mathrm{t} \mathrm{mm}$ in depth during the third step, as demonstrated in Figure 2b. In other words, when the cylindrical region of the tool sinks into the workpiece $t \mathrm{~mm}$ in depth, the volume of the evacuated material equals the volume of the scanned area, the surroundings with the F, G, H, I corners, during the first step, as seen in Figure 2b.

When we choose to use a tool without a conical region, with only a cylindrical region, sinking into the workpiece $t \mathrm{~mm}$ in depth, the total volume of the evacuated material $\left(V_{\mathrm{E}}\right)$ equals the volume of the cylindrical region $\mathrm{t} \mathrm{mm}$ in height between points $\mathrm{D}$ and $\mathrm{E}$ during the third step, as seen in Figure $\mathbf{2 b}$. The total volume of the evacuated material $\left(V_{\mathrm{E}}\right)$ can be calculated depending on the rotating and proceeding motions of the tool, material thickness $(t)$ and diameter of the hole of the cylindrical region when the tool revolves once, sinking into the workpiece as much as the feed rate $(\mathrm{mm} / \mathrm{rev})$ allows it. The volume of the evacuated material for one pass $\left(V_{1 \mathrm{R}}\right)$ is computed as shown in Equation (1).

$$
V_{1 \mathrm{R}}=\frac{\pi d^{2}}{4} \cdot f
$$

For the $\mathrm{n}$ passes of the tool, the volume of the evacuated material $\left(V_{n \mathrm{R}}\right)$ is computed with Equation (2).

$$
V_{n \mathrm{R}}=\frac{\pi d^{2}}{4} \cdot f \cdot n
$$

Therefore, when dividing Equation (2) by 60, the volume of the evacuated material, obtained in one second according to the geometry of the tool, as seen in Figure $\mathbf{2 b}$ showing the second step, Equation (3) is obtained.

$$
V_{\mathrm{E} 1 s}=\frac{\pi d^{2}}{4} \cdot f \cdot \frac{n}{60}\left(\frac{v o l^{3}}{s}\right)
$$

When the cylindrical region of the tool sinks into the workpiece between points $\mathrm{D}$ and $\mathrm{E}$, the sinking depth equals $t(\mathrm{~mm})$ and it is representable depending on the sinking time $(T)$ and speed $(v)$, as identified in Equation (4).

$$
T_{3}(\mathrm{~s})=\frac{t}{v}
$$

If the sinking time of the cylindrical region between points $\mathrm{D}$ and $\mathrm{E}$ equals $\mathrm{T}_{3}$ second, the total volume of the evacuated material is computed depending on the hole diameter $(d)$, feed rate $(f)$, revolving cycles $(n)$, material thickness $(t)$ and sinking speed $(v)$, as indicated in Equation (5).

$$
V_{\mathrm{E}}=\frac{\pi d^{2}}{4} \cdot f \cdot \frac{n}{60} \cdot \frac{t}{v}\left(\frac{v o l^{3}}{T_{\mathrm{s}}(\mathrm{s})}\right)
$$

If we obtain the value of the sinking-speed $(v)$ equation depending on the tool cylindrical region, hole diameter $(d)$ and revolving cycles $(n)$, Equation (6) is derived.

$$
v=\frac{\pi d n}{100}
$$

When including the value of $v$ (as shown in Equation (6)) in Equation (5), the $V_{\mathrm{E}}$ volume results in Equation (7).

$$
V_{\mathrm{E}}=250 \cdot d \cdot f \cdot t
$$

The volume of the material being evacuated by the conical region before the tool sinks into the workpiece between AI and CI in the first step, as shown in Figure $\mathbf{2 b}$, equals the volume of the conical region between points AI and CI. Thus, this volume is computable with Equation (8).

$$
V_{\mathrm{C}}=\frac{t^{3}}{24} \cdot \tan ^{2} \beta
$$

By subtracting the conical-region volume $\left(V_{\mathrm{C}}\right)$ from the total volume of the evacuated material $\left(V_{\mathrm{E}}\right)$, the volume of the material $\left(V_{\mathrm{B}}\right)$, shaping the bushing, is derivable. The bushing volume $\left(V_{\mathrm{B}}\right)$ equals the volume of the area, surrounding the $\mathrm{F}, \mathrm{G}, \mathrm{H}$, and I corners during the first step, as seen in Figure $\mathbf{2 b}$. The volume of the bushing $\left(V_{\mathrm{B}}\right)$ is analyzed in detail in section 2.3 .

\subsection{Volume of the evacuated material and the bushing formation}

The evacuated material, represented by the blue part in Figure 3a, generates the flake on the upper surface and bushing on the bottom surface, in the thermal-friction-drilling operations. A substantial amount of the evacuated material is converted into the flake and bushing formations, but a small amount of this material extends to the surroundings. Thus, the evacuated-material volume $\left(V_{\mathrm{E}}\right)$ depends on the volume of bushing $\left(V_{\mathrm{B}}\right)$, flake $\left(V_{\mathrm{F}}\right)$ and the material extended to the sur- 

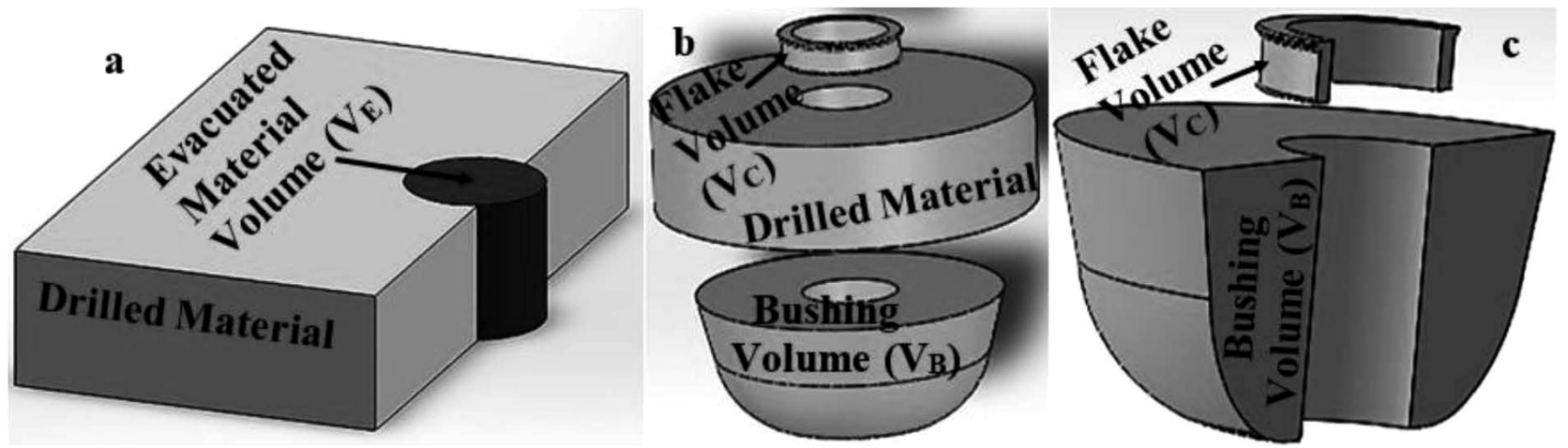

Figure 3: Volume of the evacuated material: a) evacuated material, b) the flake and bushing, c) a sectional view of the flake and bushing

roundings $\left(V_{\mathrm{S}}\right)$. The volume of the evacuated material can be written as Equation (9).

$$
V_{\mathrm{E}}=V_{\mathrm{C}}+V_{\mathrm{B}}+V_{\mathrm{S}}
$$

However, in the volume calculation, the volume of the material spread to the surroundings can be ignored due to its small amount, which is not worth to be taken into account. When the volume of the material spread to the surroundings is negligioble, Equation (9) can be rewritten as Equation (10).

$$
V_{\mathrm{E}}=V_{\mathrm{C}}+V_{\mathrm{B}}
$$

The softened material flows towards the upper side to form the flake until the tip of the tool reaches the half depth of the material thickness. As seen in Figure 3b, once the tip of the tool has passed the half distance of the material thickness, the softened material starts to flow downward to constitute the bushing formation. When the volume of the material spread to the surroundings is negligible, all the evacuated material generates the flake and the bushing, as shown in Figure 3c.

\subsection{Related rate equations of the bushing shape}

In the sections below, we give some related rate equations of the bushing shape, that is, we establish some differential equations to calculate the instantaneous rate of change of volume $(V)$ with respect to time $(T)$. As seen in Figure $4 \mathbf{a}$, the tip of the tool is proceeding into the workpiece from the time when $T=0$ until $T=T_{0}$. Thus, the depth of the tip of the tool proceeding into the workpiece can be expressed depending on $t_{1}$ as $h_{1}=h_{1}(t)$. While the tip of the tool is proceeding into the workpiece, the $h_{1}$ depth changes from 0 to $t_{1}\left(0 \leq h_{1} \leq t_{1}\right)$ from the beginning when the tip of the tool contacts the surface until the entire tip of the tool enters the workpiece $\left(0 \leq T \leq T^{0}\right)$. In this case, the change in the $h_{1}$ depth can be identified depending on the material thickness $(t)$, as $d_{\mathrm{h} 1} / d_{\mathrm{t}}=1$. The volume of the tip of the tool $\left(V_{\mathrm{M}}\right)$ is computable depending on the tool proceeding time and material thickness as in Equation (11).

At the time when $T=T_{0}$ and $h_{1}=t_{1}$, the change in the volume of the material evacuated by the tip of the tool can be calculated as seen in Equation (11), depending on the material thickness and process time.

$$
\begin{aligned}
& V_{\mathrm{M}}=\frac{1}{3} \pi h_{1}^{2} h_{1} \Rightarrow \frac{d_{\mathrm{VM}}}{d_{\mathrm{T}}}=\frac{1}{3} \pi h_{1}^{2} \frac{d_{\mathrm{h} 1}}{d_{\mathrm{T}}}=\frac{1}{3} \pi h_{1}^{2} \Rightarrow \\
& \Rightarrow V_{\mathrm{M}}=\frac{1}{3} \pi t_{1}^{2} t=\frac{\pi}{3} t^{3}
\end{aligned}
$$

The volume of the material evacuated by the conical region of the tool, similar to the frustum of a cone, is seen in Figure $\mathbf{4 b}$. The depth of the frustum of the cone
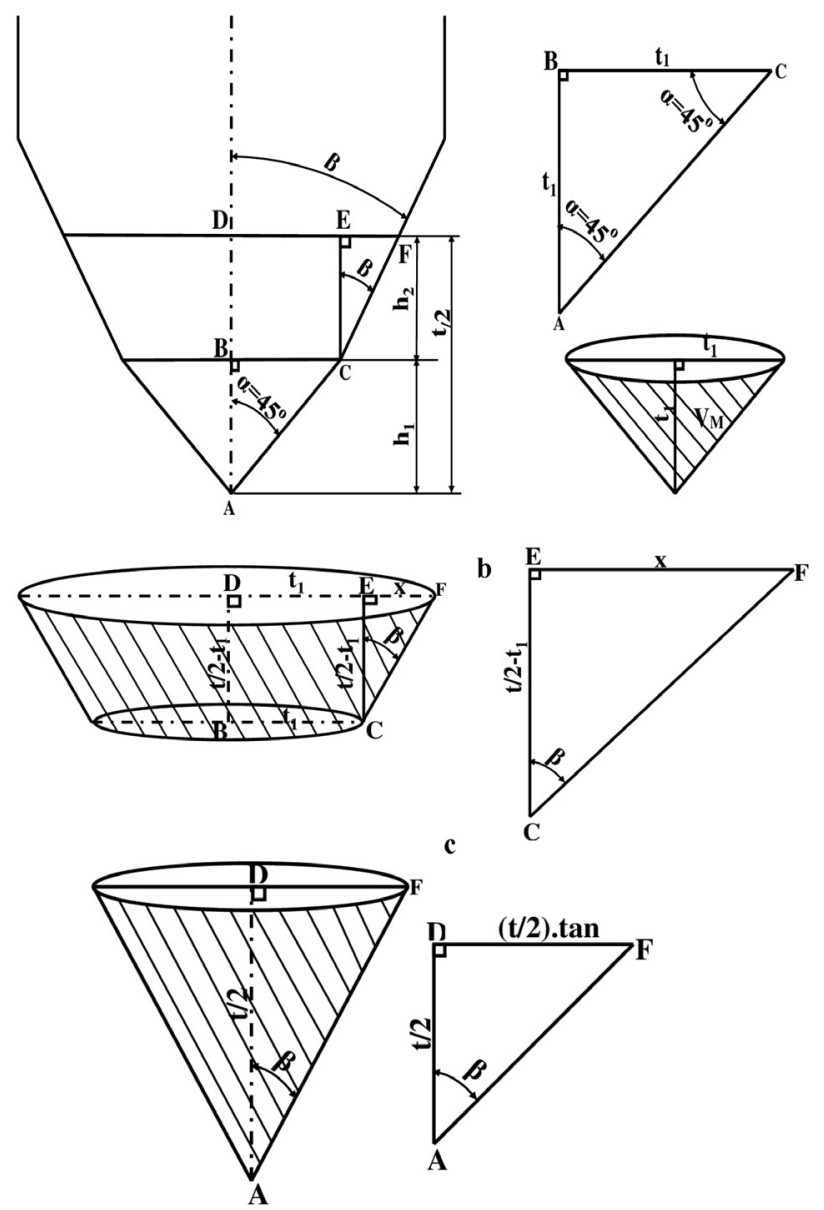

Figure 4: Volume of the tip of the tool: a) tip of the tool, b) frustum of a cone, c) a tool without the tip 
$\left(h_{2}\right)$ enters the workpiece depending on the height of the tip of the tool and material thickness as $t_{1} \leq h_{2} \leq(t / 2-$ $\left.t_{1}\right)$, during the time between $T_{0}$ and $T_{1}\left(T_{0} \leq T \leq T_{1}\right)$. $\left|E_{\mathrm{F}}\right|$ distance $(x)$ can be expressed depending on the height of the tip of the tool $\left(t_{1}\right)$, material thickness $(t)$ and tool conical angle $(\beta)$, as in Equation (12).

$$
t_{1}+x=t_{1}\left(\frac{t}{2}-t_{1}\right) \tan \beta \Rightarrow x=\left(\frac{t}{2}-t_{1}\right) \tan \beta
$$

The volume of the material, evacuated by the frustum of the cone region of the tool is computable depending on the height of the tip of the tool $\left(t_{1}\right)$, material thickness $(t)$, and tool conical angle $(\beta)$, as in Equation (13) where $d_{\mathrm{h} 1} / d_{\mathrm{t}}=1$.

$$
V_{\mathrm{FC}}=\frac{1}{3} \pi h_{2}^{2}\left[t_{1}^{2}+t_{1}\left(t_{1}\left(\frac{t}{2}-t_{1}\right) \tan \beta\right)+\left(t_{1}+\left(\frac{t}{2}-t_{1}\right) \tan \beta\right)^{2}\right]
$$

While the frustum of the tool-cone region is proceeding into the workpiece, the volume of the material evacuated at any time between $T_{0} \leq T \leq T_{1}$ is calculable as in Equation (14).

$$
\frac{d_{\mathrm{VFC}}}{d_{\mathrm{T}}}=\frac{1}{3} \pi\left[t_{1}^{2}+t_{1}\left(\frac{t}{2}-t_{1}\right) \tan \beta+\left(t_{1}+\left(\frac{t}{2}-t_{1}\right) \tan \beta\right)^{2}\right] \frac{d_{\mathrm{h} 2}}{d_{\mathrm{T}}}
$$

As seen in Figure $\mathbf{4 c}$, if the inclination angle of the tip of the tool $(\alpha)$ is equal to the conical angle $(\beta)$, the small amount of the evacuated material $\left(V_{\mathrm{MN}}\right)$ is negligible. To calculate the volume of the material evacuated by the conical region of the tool over the period starting when the tip of the tool contacts the workpiece surface to the point when the tip of the tool reaches the half thickness of the material $(t / 2)\left(0 \leq T \leq T_{1}\right)$, Equation (15) is used.

$$
V_{\mathrm{C}}=\frac{1}{3} \pi \frac{t^{3}}{2} \tan \beta
$$

The volume of the evacuated material, at any time, from the beginning to $T_{1}$, when the tip of the tool reaches to the half thickness of the material $(t / 2)\left(0 \leq T \leq T_{1}\right)$,
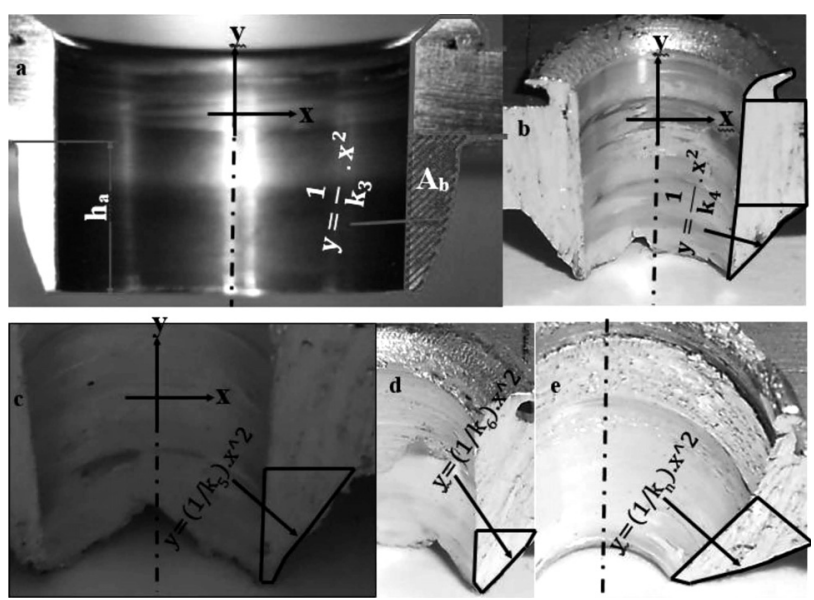

Figure 5: Bushing shape obtained with experiments and literature studies, a), ${ }^{6}$ b-e $)^{9,10,13,14}$ can be calculated with Equation (16), depending on the material thickness $(\mathrm{t})$ and tool conical angle $(\beta)$.

$$
\begin{aligned}
& \frac{d_{\mathrm{VC}}}{d_{\mathrm{T}}}=\frac{1}{3} \pi \frac{t^{2}}{2} \operatorname{an} \beta \frac{d_{\mathrm{h}}}{d_{\mathrm{T}}} \Rightarrow \text { as } \frac{d_{\mathrm{h}}}{d_{\mathrm{T}}}=1 \Rightarrow \\
& \Rightarrow \frac{d_{\mathrm{VC}}}{d_{\mathrm{T}}}=\frac{1}{3} \pi \frac{t^{2}}{2} \text { an } \beta
\end{aligned}
$$

\subsection{Geometrical modeling of the bushing shape}

The features of a bushing shape, especially the geometrical dimensions of a bushing formation, such as the bushing height and wall thickness, are very important in order to provide for an increasing connection strength during the thermal friction drilling of sheet materials. In Figure 5, the outer profiles of the bushings obtained from literature studies are shown (Figure 5a to 5e). The curves of the outer profiles of the bushings bear a resemblance to a parabola. Therefore, a bushing shape can be modelled geometrically using these parabola curves, depending on the volume of the material evacuated from the thermally drilled material and the volume of the bushing. The slopes of these curves show distinctions. These distinctions can be identified with an inverse to impact of the constant, symbolized as $(k)$. The sloping curve of the outer shape of the bushing changes according to the selected parameters, such as the hole diameter, material thickness, spindle speed, feed rate, properties of the conical tool and thermal-friction-drilled material.

The curves of the bushings can be represented by parabola curve equations, as seen in Figures 6 and 7. These curve equations can be written as parabola equations with an inverse to impact of the constant $(k)$. As seen in Figures 6 and 7, the bushing height changes while the slopes of the parabola curves change. The slopes of the parabola curves are determined by the values of the constant value $(k)$ changing from $k_{1}$ to $k_{\mathrm{n}}$ so that $0<k_{1}<k_{2}<k_{3} \ldots<k_{\mathrm{n}}<8$.

If the section area $(\mathrm{AB})$ in Figure 7, in blue color, is rotated around the $\mathrm{y}$ axis, the volume equation of the

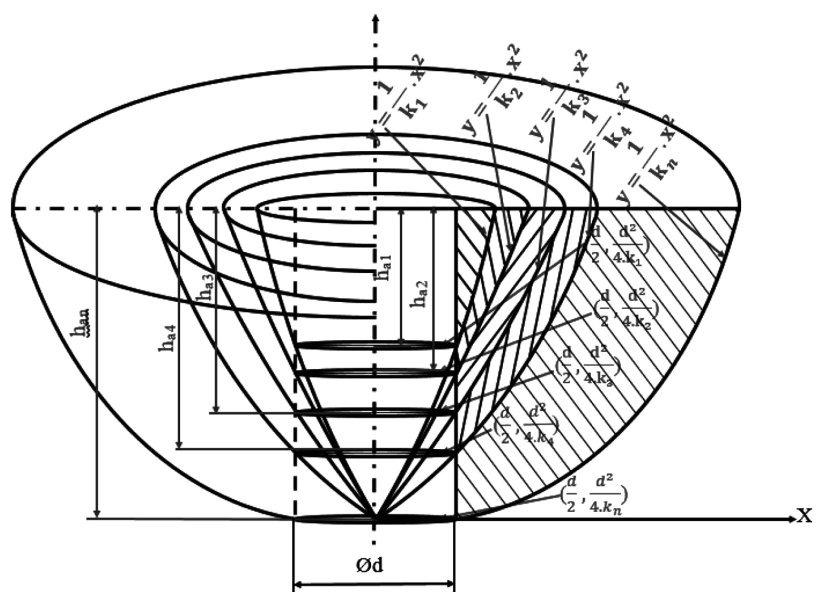

Figure 6: Shape of the outer curve of the bushings 
bushing can be calculated as in Equations from (17) to (20). In order to calculate the volume of the bushing $\left(V_{\mathrm{A}}\right)$ by rotating the $(\mathrm{AB})$ around axes $\mathrm{y}$, the $x$ in Equation (17) must be written depending on the equation constant $(k)$ and $y$, as seen in Equation (18).

$$
\begin{aligned}
& y=\frac{1}{k} x^{2} \\
& x=\sqrt{k y}
\end{aligned}
$$

By rotating the section area $(\mathrm{AB})$ of the bushing around the $y$ axis, the volume of the bushing $\left(V_{\mathrm{B}}\right)$ can be calculated using the integral of the rotating body's method, as seen in Equation (19).

$$
V_{B}=\pi \int_{0}^{h_{a}}\left[(\sqrt{k y})^{2}-\left(\frac{d}{2}\right)^{2}\right] d_{y}
$$

By solving Equation (11), the volume of the bushing shape $\left(V_{\mathrm{B}}\right)$ can be obtained depending on the equation constant $(k)$, thermal-friction-drilled hole diameter $(d)$ and bushing height $\left(h_{\mathrm{a}}\right)$ as written in Equation (20).

$$
V_{B}=\pi\left[\frac{k}{2} h_{\mathrm{a}}^{2}-\frac{d}{4} h_{\mathrm{a}}\right]
$$

In Figure 8, the curves of the parabolas, similar to the outer curve of the bushing height, are shown. These curves were obtained by applying the natural-algorithm method to Equation (22), using the MATLAB software program.

\section{MATERIALS AND METHODS}

In this study, the bushing-height values found in the literature were taken into account. In this regard, for the calculation procedure, these bushing-height values were selected. The minimum and maximum bushing-height values obtained from the literature are shown in Table 1. ${ }^{10,13,14}$

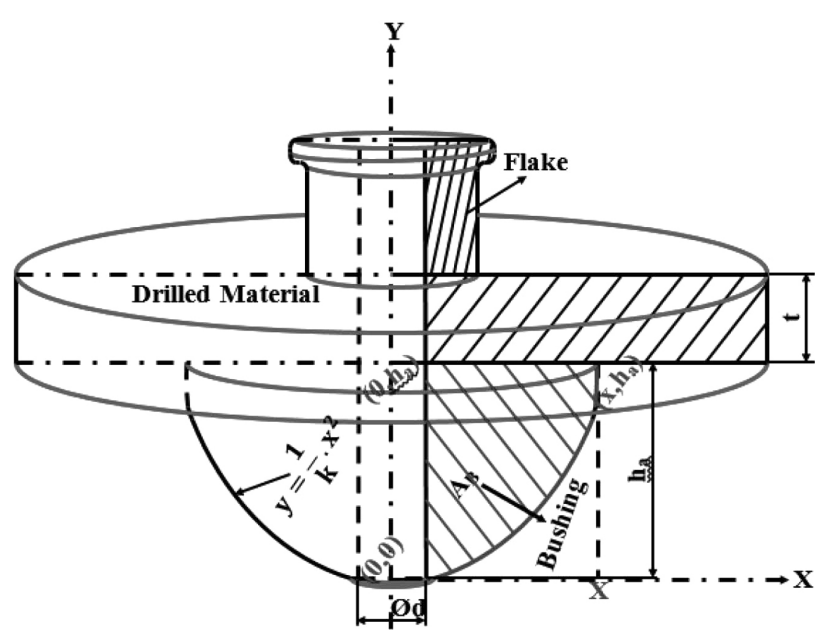

Figure 7: Obtaining the curve-shape equation for a bushing in thermal

\begin{tabular}{|c|c|c|c|c|c|c|}
\hline \multirow{3}{*}{$\begin{array}{l}\text { Material } \\
\text { thickness } \\
(t)(\mathrm{mm})\end{array}$} & \multicolumn{6}{|c|}{ Hole diameters $(\varnothing d)(\mathrm{mm})$} \\
\hline & \multicolumn{2}{|c|}{$\emptyset d=8 \mathrm{~mm}$} & \multicolumn{2}{|c|}{$\varnothing d=10 \mathrm{~mm}$} & \multicolumn{2}{|c|}{$\varnothing d=12 \mathrm{~mm}$} \\
\hline & $\begin{array}{c}\text { Min. } \\
\left(h_{\mathrm{a}}\right)\end{array}$ & $\begin{array}{c}\operatorname{Max} . \\
\left(h_{\mathrm{a}}\right)\end{array}$ & $\begin{array}{c}\text { Min. } \\
\left(h_{\mathrm{a}}\right)\end{array}$ & $\begin{array}{c}\operatorname{Max} . \\
\left(h_{\mathrm{a}}\right)\end{array}$ & $\begin{array}{c}\text { Min. } \\
\left(h_{\mathrm{a}}\right)\end{array}$ & $\begin{array}{c}\text { Max. } \\
\left(h_{\mathrm{a}}\right)\end{array}$ \\
\hline $\mathrm{t}=2 \mathrm{~mm}$ & 4.86 & 5.59 & 5.58 & 6.86 & 5.74 & 7.13 \\
\hline $\mathrm{t}=4 \mathrm{~mm}$ & 5.03 & 6.64 & 6.06 & 7.74 & 8.34 & 9.04 \\
\hline $\mathrm{t}=6 \mathrm{~mm}$ & 5.22 & 6.75 & 6.11 & 8.40 & 8.62 & 9.16 \\
\hline
\end{tabular}
friction drilling
Table 1: The maximum and minimum values of bushing heights gained from the literature

Furthermore, in the literature, there are two other papers, in which the bushing heights are discussed. In reference $^{12}$, the St 52 steel material with a depth of $2 \mathrm{~mm}$ was drilled, making a diameter of $6.7 \mathrm{~mm}$ using the thermal-friction-drilling method. In this study, only 5-mm and 4-mm bushing heights obtained at feed rates of $100 \mathrm{~mm} / \mathrm{rev}$ and $500 \mathrm{~mm} / \mathrm{rev}$, respectively, were identified. However, the bushing-height results obtained in paper $^{3}$ are not consistent with the results from Table 1. Some remarks about this inconsistency are in order. In that paper, the thermal-friction-drilling method applied to the AISI 304 stainless steel material with depths of $2 \mathrm{~mm}$ and $3 \mathrm{~mm}$ was drilled using conical tools with diameters of $\left(5.4,7.3\right.$ and 9.2) mm. In paper, ${ }^{3}$ the mean bushing height of approximately $8.5 \mathrm{~mm}$ was gained at a diameter of $7.3 \mathrm{~mm}$ and a depth of $3 \mathrm{~mm}$. Moreover, the author gained a bushing height (length) of $10.86 \mathrm{~mm}$ using a hole diameter of $9.2 \mathrm{~mm}$ and material depth of $3 \mathrm{~mm}$. However, in Table 1, a bushing height of $9.16 \mathrm{~mm}$ is obtained as the maximum value for the thermal friction drilling of the A7075-T651 alloy with a depth of $6 \mathrm{~mm}$ in and a hole diameter of $12 \mathrm{~mm}$. According to the analysis of the results obtained either here or in the previous studies, it looks that in study ${ }^{3}$ the author did not verify his/her results with experiments, but instead adjusted them according to the previous results stating that "the bushing height is noticed to be approximately 2-3 times the thickness of the thermal friction drilled material". ${ }^{7,8}$ The result assumed in study ${ }^{3}$

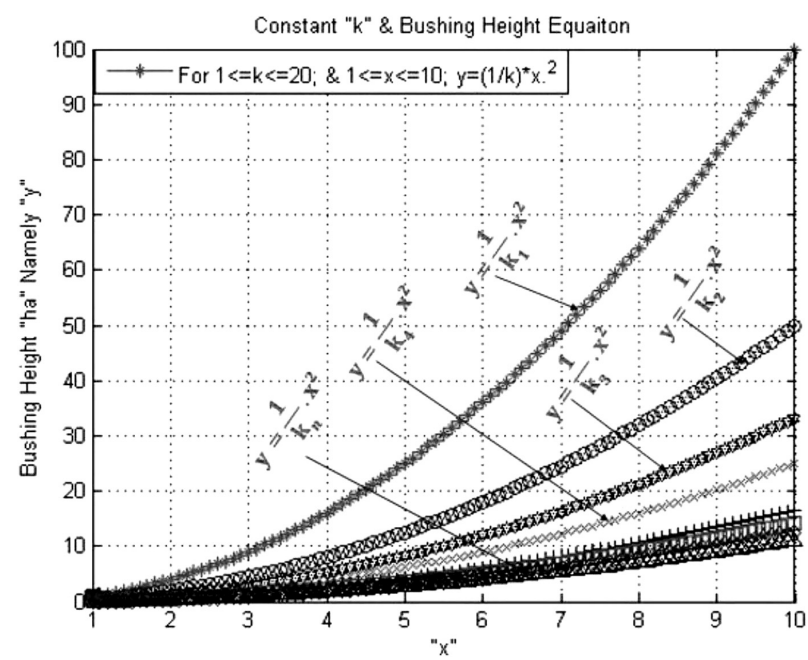

Figure 8: Curves of the parabolas gained with a natural algorithm via the MATLAB software 
is not achievable at all. Thus, the mathematical model of geometrical modeling of the bushing-height Equation (14) given in the present paper should not be tested against the results obtained in study ${ }^{3}$ to avoid any inconsistency.

\section{RESULTS AND DISCUSSION}

According to the shape of the outer curve of the bushing shape, the bushing height $\left(h_{\mathrm{a}}\right)$ is calculable depending on the bushing volume $\left(V_{\mathrm{B}}\right)$, while subtracting the volume $\left(V_{\mathrm{C}}\right)$ of the tool conical region, sinking into the workpiece as soon as the tip of the tool reaches the half thickness of the material $(t / 2)$, from the total volume of the evacuated material as demonstrated in Equation (21). The bushing height value $\left(h_{\mathrm{a}}\right)$ can be written as shown in Equation (22).

$$
V_{\mathrm{E}}-V_{\mathrm{C}}=V_{\mathrm{B}}
$$

If Equation (7) is solved according to $\left(h_{\mathrm{a}}\right)$, the bushing-height value $\left(h_{\mathrm{a}}\right)$ can be determined as seen in Equation (14).

$$
\begin{aligned}
& 250 \cdot \pi t f d-\pi \frac{t^{3}}{24} \tan ^{2} \beta=\pi\left[\frac{k}{2} h_{\mathrm{a}}^{2}-\frac{d^{2}}{4} h_{\mathrm{a}}\right\rceil \Rightarrow \\
& \Rightarrow k=\frac{500 \cdot t f d-\frac{t^{3}}{12} \tan ^{2} \beta+\frac{d^{2}}{2} h_{\mathrm{a}}}{h_{\mathrm{a}}^{2}}
\end{aligned}
$$

The relationships between the equation constant $(k)$ and hole diameter $(d)$, as well as the ones between the equation constant $(k)$ and material thickness $(t)$, feed rate $(f)$ and tool conical angle $(\beta)$ were analyzed. According to these relationships between the equation constant $(k)$ and other selected parameters, the value of the equation constant $(\mathrm{k})$ is determined depending on the hole diameter $(d)$, material thickness $(t)$, feed rate $(f)$ and tool conical angle $(\beta)$, as written in Equation (24), according to the experimental bushing-height values from the literature, shown as $\left(h_{\mathrm{a}}\right)$ results in Table 1 . The values of constants $\varepsilon, \theta, \delta$, and $\lambda$ were written as shown in Equation (23), depending on the equation constant $(\mathrm{k})$, material thickness $(\mathrm{t})$, conical angle $(\beta)$, hole diameter $(d)$ and feed rate $(f)$.

$$
\frac{k}{d}=\varepsilon ; \quad \frac{k}{t}=\theta ; \quad \frac{k}{\beta}=\delta ; \quad \frac{k}{f}=\lambda
$$

It was found that the values of constants $\varepsilon, \theta, \delta$, and $\lambda$ were changed between 0.01-1.2. Therefore, these equation constant values can be clarified with one symbol, as $\mu$. In this case, the equation constant values can be written as $0.01 \leq \mu \leq 1.2 . \theta, \delta$, and $\lambda$ equation constants showed narrower range limits than the $\varepsilon$ equation constant, namely, $0.01<\theta, \delta$, and $\lambda<1.2$, but equation constant $\varepsilon$ showed a wider range, $0.01 \leq \varepsilon \leq 1.2$. Thus, Equation (15) can be rearranged by selecting equation constant $\mu$, depending on the relationship between the $\mathrm{k}$ constant and hole diameter $(k=\mu \cdot d)$; then, by solving the obtained equation according to the bushing height $\left(h_{\mathrm{a}}\right)$, as a second-degree equation, the bushing height equation is gained as seen in Equation (24).

$$
h_{a}=\frac{d}{4 \mu}+\sqrt{\frac{d^{2}}{16 \mu^{2}}-\frac{t^{3} \tan ^{2} \beta}{12 d \mu}+\frac{500 \cdot t f}{d \mu^{2}}}
$$

The bushing-height $\left(h_{\mathrm{a}}\right)$ value can be theoretically calculated with Equation (10), depending on the hole diameter $(d)$, feed rate $(f)$, material thickness $(t)$, tool conical angle $(\beta)$ and equation constant $(\mu)$. Figures 9a to $9 \mathbf{c}$, and $9 \mathbf{d}$ show fitted line plots of the feed rate $(f)$, material thickness $(t)$, hole diameter $(d)$ and tool conical angle $(\beta)$ with the equation constant $(\mu)$, respectively. There is an inverse proportion between the feed rate $(f)$ and equation constant $(\mu)$, as seen in Figure 9a. With the feed-rate $(f)$ values changing between $0.01-2 \mathrm{~mm} / \mathrm{rev}$, the equation constant $(\mu)$ changes from $0.01-1.2$. However, in real application operations, generally, feed-rate $(f)$ values are selected between $0.025 \mathrm{~mm} / \mathrm{rev}$ and 0.4 $\mathrm{mm} / \mathrm{rev}$ when the equation constant $(\mu)$ has a value of approximately $0.1-0.4$, as seen in the fitted line plot in Figure 9a. Blue points show the alterations in the equation constant $(\mu)$ for the selected feed-rate values $(f)$. At a constant selected feed rate $(f)$, the bushing height increases linearly with the increasing equation constant $(\mu)$. However, when higher values are selected for the equation constant $(\mu)$, lower feed-rate values must be selected, and vice versa, because of the inverse relationship between the feed rate $(f)$ and equation constant $(\mu)$.

In Figure 9a, the deviation quantity of the fitted line plot between the theoretical and experimental bushing height, obtained from the literature, is 0.268359 in the case when the values of $\mu$ are between $0.01-1.2$; especially according to the fitted-line graph, these values show alterations of approximately $0.1-0.4$. The compatibility between the theoretical and experimental bushing-height values from the literature is increased as $\mu$ has values of $0.1-0.4$. Additionally, in all the conditions, the $P$ values are equal to 0.028 and 5.75 , respectively. Especially when the value of $P(0.028)$ is smaller than 0.05 , the effect of the feed rate on the equation constant is scientifically valid.

According to the fitted line plots in Figures 9b to 9d, the equation constant $(\mu)$ shows a collateral relationship with the material thickness $(t)$, hole diameter $(d)$ and tool conical angle $(\beta)$. This relationship shows that by selecting higher hole diameter $(d)$, material thickness $(t)$ and tool conical angle $(\beta)$, equation-constant values must be selected for $(\mu)$.

In Figures $9 \mathbf{b}$ to $9 d$, the deviation quantities of the fitted line plots between theoretical and experimental bushing heights obtained from the literature are $0.0837760,0.0238025$ and 0.0325050 , with the changing material thickness $(t)$, hole diameter $(d)$ and tool conical angle $(\beta)$, respectively. Furthermore, $P$ values are 0.000 , 0.000 , and 0.002 ; all of them are smaller than 0.05 . F values are $122.44,4106.95$, and 17.77 , with the selected 

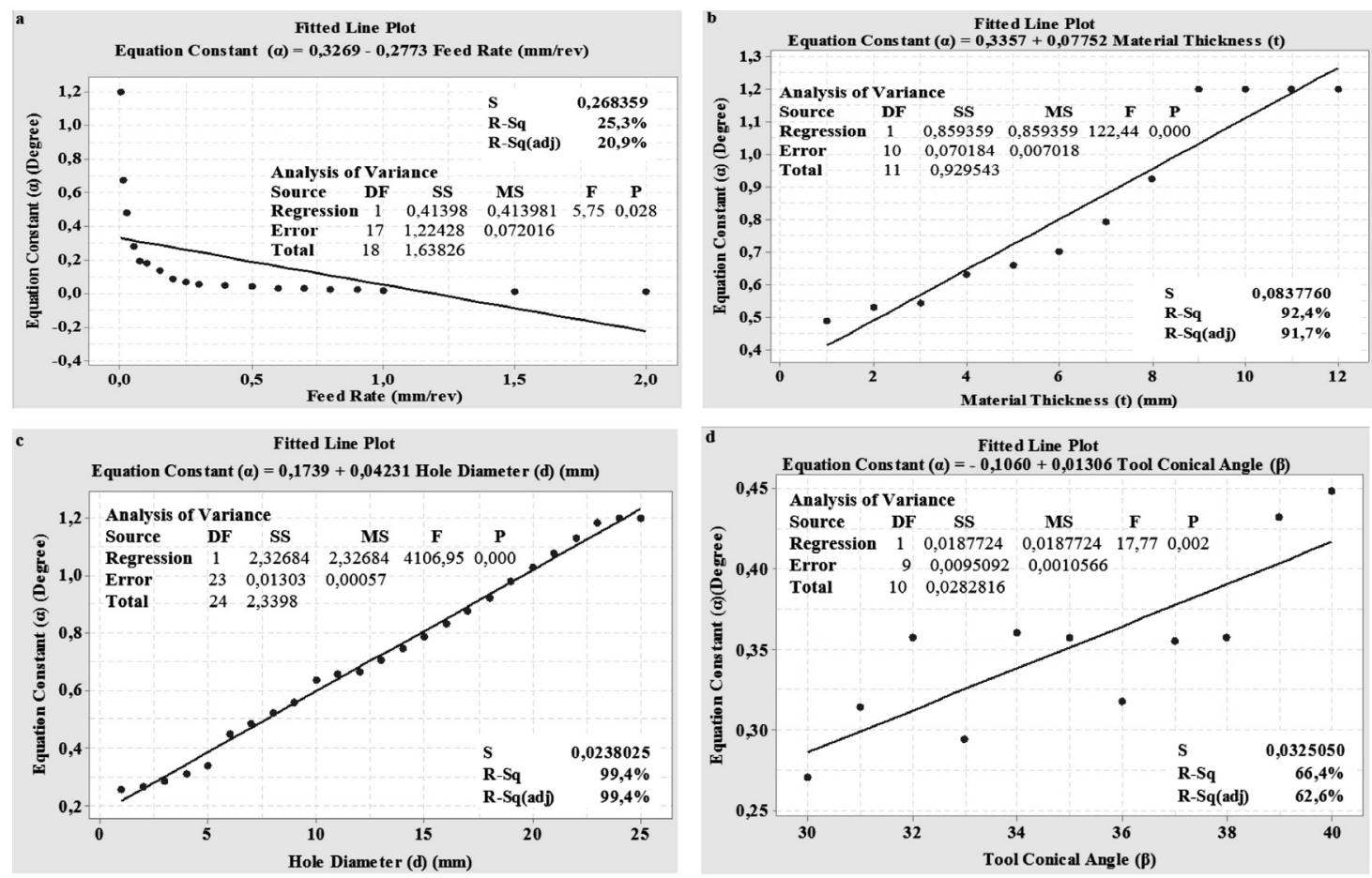

Figure 9: Fitted line plots of the equation constant $(\mu)$ with: a) feed rate $(f)$, b) material thickness $(t)$, c) hole diameter $(d)$, d) tool conical angle $(\beta)$

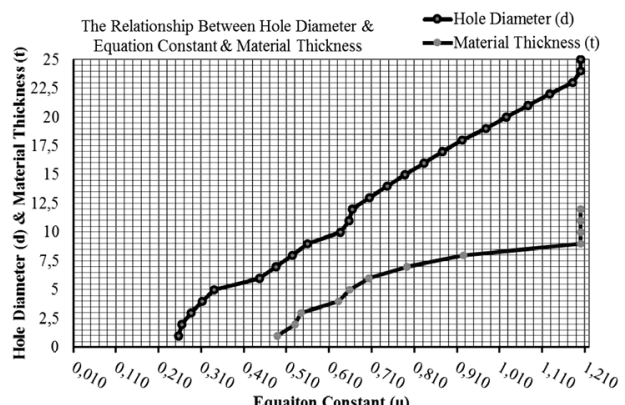

The Relationship Between Feed Rate \& Equation Constan

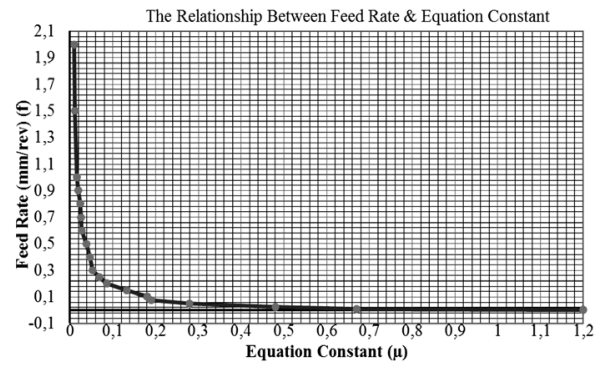

The Relationship Between Tool Conical Angle \& Equation Constan

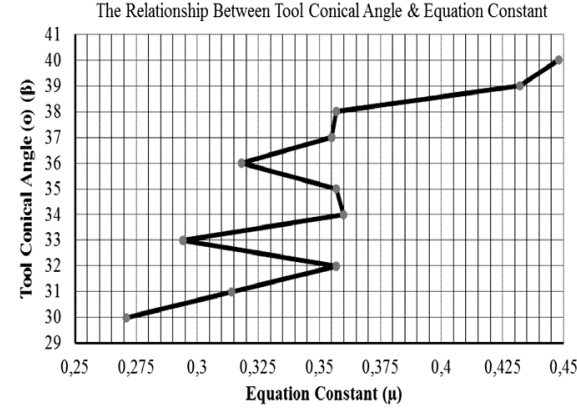

Figure 10: Changing the equation-constant values $(\mu)$ depending on: a) hole diameter $(d)$ and material thickness $(t)$, b) feed rate $(f), c)$ tool conical angle $(\beta)$ material thickness $(t)$, hole diameter $(d)$ and tool conical angle $(\beta)$, respectively. These results show that the most effective parameter for the equation constant $(\mu)$ and bushing height $\left(h_{\mathrm{a}}\right)$ is the hole diameter $(d)$, followed by material thickness $(t)$ and tool conical angle $(\beta)$. Consequently, the least effective parameter for the equation constant $(\mu)$ and bushing height $\left(h_{\mathrm{a}}\right)$ shows an inverse relationship only with the equation constant $(\mu)$.

In Figures 10a to 10c, the graphs of the equation constant $(\mu)$ with the hole diameter $(d)$, material thickness $(t)$, feed rate $(f)$ and tool conical angle $(\beta)$ are shown, respectively. When an operator intends to calculate the bushing-height value, depending on the selected parameters such as the hole diameter $(d)$, material thickness $(t)$, feed rate $(f)$ and tool conical angle $(\beta)$ using Equation (10), s/he can select the equation-constant value $(\mu)$ from the graphs in Figures 10a to 10c.

According to Figures 10a to 10c, the equationconstant values $(\mu)$ are between $0.25-1.2,0.49-1.2$, $0.1-0.3$, and $0.275-0.45$ with the changing hole diameter $(d)$, material thickness $(t)$, feed rate $(f)$ and tool conical angle $(\beta)$, respectively. In other words, the bushingheight equation-constant $(\mu)$ values can be selected between $0.25-1.2,0.49-1.2,0.1-0.3$, and $0.275-0.45$ according to the hole diameter $(d)$, material thickness $(t)$, feed rate $(f)$ and tool conical angle $(\beta)$, respectively.

\section{CONCLUSIONS}

The bushing formation is the main purpose of thermal friction drilling as it increases the connection 


\section{Z. DEMIR: A GEOMETRICAL APPROACH TO DERIVING A BUSHING HEIGHT EQUATION FOR THERMAL ...}

strength of sheet materials. Therefore, bushing shapes were analyzed and modelled geometrically. The outer curve of the bushing resembled a parabola, thus the equation of the bushing shape was obtained depending only on the hole diameter $(d)$, material thickness $(t)$, feed rate $(f)$, tool conical angle $(\beta)$ and equation constants $(\mu)$. It was confirmed that the values of the constant $(\mu)$ were between 0.01-1.2.

By equalizing the bushing volume $\left(V_{\mathrm{B}}\right)$ to the difference between the total volume of the evacuated material $\left(V_{\mathrm{E}}\right)$ and the volume of the material evacuated before the tip of the tool reaches the half thickness $(t / 2)$, while the tool is proceeding into the workpiece, the bushing-height equation is written depending on the parameters such as the hole diameter $(d)$, material thickness $(t)$, feed rate $(f)$, tool conical angle $(\beta)$ and equation constant $(\mu)$, which can be selected by the operator, as seen in Equation (10).

The most effective parameter for the bushing height $\left(h_{\mathrm{a}}\right)$ and equation constant $(\mu)$ is the hole diameter $(d)$, followed by the material thickness $(t)$, feed rate $(f)$ and tool conical angle $(\beta)$. Bushing-height equation-constant $(\mu)$ values are between 0.01-1.2 depending on all the selected parameters, but they can be selected between $0.25-1.2,0.49-1.2,0.1-0.3$ and $0.275-0.45$ with respect to the hole diameter $(d)$, material thickness $(t)$, feed rate $(f)$ and tool conical angle $(\beta)$.

An operator can calculate the bushing height theoretically using Equation (10), depending on the parameters such as the hole diameter $(d)$, material thickness $(t)$, feed rate $(f)$ and tool conical angle $(\beta)$, without carrying out experiments. Moreover, it allows researchers and manufacturers to predict the optimum bushing height $\left(h_{\mathrm{a}}\right)$ according to the selected parameters prior to starting the friction-drilling process.

\section{REFERENCES}

${ }^{1}$ A. A. Eliseev, S. V. Fortuna, E. A. Kolubaev, T. A. Kalashnikova Microstructure modification of 2024 aluminum alloy produced by friction drilling, Mater. Sci. Eng., 691 (2017), 121-25, doi:10.1016/ j.msea.2017.03.040
${ }^{2}$ Z. Demir, C. Özek, Investigate the effect of pre-drilling in friction drilling of A7075-T651, Mater. Manuf. Proc., 29 (2014), 593-599, doi:10.1080/10426914.2014.892986

${ }^{3}$ S. A. El-Bahloul, H. E. El-Shourbagy, A. M. El-Bahloul, T. T. El-Midany, Experimental and thermo-mechanical modeling optimization of thermal friction drilling for AISI 304 stainless steel, CIRP J. Manuf. Sci. Technol., 20 (2018), 84-92, doi:10.1016/j.cirpj. 2017.10.001

${ }^{4}$ J. A. van Geffen, Rotatable piercing tools for forming bossed holes, USA Patent 4.185.486. (1980)

${ }^{5}$ S. F. Miller, R. Li, H. Wang, A. J. Shih, Experimental and numerical analysis of the friction drilling process, J. Manuf. Sci. Eng., 128 (2006), 802-810, doi:10.1115/1.2193554

${ }^{6}$ S. M. Lee, H. M. Chow, F. Y. Huang, B. H. Yan, Friction drilling of austenitic stainless steel by uncoated and PVD $\mathrm{AlCrN}-$ and TiAlN-coated tungsten carbide tools, Int. J. Mach. Tools Manuf., 49 (2009), 81-88

${ }^{7}$ G. Dekkers, Flowdrill, Copyright by Flow Drill B. V. Holland, 2003, $1-30$

${ }^{8}$ M. Matsuoka, M. Motoyoshi, M. Sakaguchi, A. Shinohara, T. Shigeede, Y. Saito, M. Matsuda, N. Shimizu, Friction heat during self-drilling of an orthodontic miniscrew, Int. J. Oral Max. Surg., 40 (2011) 2, 191-194

${ }^{9}$ C. Özek, Z. Demir, Investigate the surface roughness and bushing shape in friction drilling of A7075-T651 and St 37 steel, TEM J., 2 (2013), 170-180

${ }^{10} \mathrm{Z}$. Demir, C. Özek, Investigation of the bushing height and wall thickness in friction drilling of A7075-T651 alloy with and without a hole, Nation. Mach. Manuf. Symp., Bursa, 2014, 113-127

${ }^{11}$ C. Özek, Z. Demir, Investigation of the effect of experimental parameters on the friction drilling of A7075-T651 aluminum alloy, Firat Univ. J. Eng., 25 (2013) 1, 39-47

${ }^{12}$ M. T. Kaya, A. Aktas, B. Beylergil, H. K. Akyildiz, An experimental study on friction drilling of ST12 steel, Trans. Can. Soc. Mech. Eng., 38 (2014) 3, 319-329

${ }^{13}$ C. Özek, Z. Demir, Bushing height according to material thickness. Dicle Univ. J. Eng., 4 (2013) 2, 61-67

${ }^{14} \mathrm{Z}$. Demir, Investigate the temperature and bushing shape in predrilling friction drilling of A7075-T651, $2^{\text {nd }}$ Int. Iron and Steel Symp. (IISS'15), Karabuk, 2015, 381-389

${ }^{15}$ W. L. Ku, C. L. Hung, S. M. Lee, H. M. Chow, Optimization in thermal friction drilling for SUS 304 stainless steel, Int. J. Adv. Manuf. Technol., 53 (2011), 935-944

${ }^{16}$ S. F. Miller, J. Tao, A. J. Shih, Friction drilling of cast metals, Int. J. Mach. Tools Manuf., 46 (2006), 1526-1535, doi:10.1016/j.ijmachtools.2005.09.003 